\title{
AVALIAÇÃO DE ISOLADOS DE Lentinula edodes(BERK) PEGLER (SHIITAKE) EM DIFERENTES SUBSTRATOS
}

\section{Avaluation of Isolated Lentinula edodes (BERK) Pegler (Shiitake) in Diferent Substracts.}

\author{
Renato Tratch ${ }^{1}$ \\ Gilson Schroeder Keiser ${ }^{2}$
}

\section{Resumo}

Realizou-se este trabalho visando a selecionar isolados adaptados à região e com produção constante ou com produção definida de inverno e verão, além de substratos (toras) de espécies comuns na região (eucalipto „,bracatinga) e com grande eficiência biológica. Os ensaios de campo foram realizados na Fazenda Experimental Gralha Azul - PUCPR, e a produção de "sementes" no Laboratónio de Fitopatologia. Para a avaliação, as toras de eucalipto e bracatinga foram colocadas em forma de delineamento experimental, representadas por um fatorial $3 \times 2 \times 4$, sendo 3 isolados, 2 substratos (toras de eucalipto e toras de bracatinga) e 4 repetições. As toras de bracatinga não foram colonizadas pelos isolados testados e não ocorreu diferença estatística significativa na produção entre os isolados.

Palavras-chave: Bracatinga; Eucalipto; Shiitake.

\section{Abstract}

The present work was done with the objective of selecting isolated adapted to the region and with either constant or seasonal (winter and summer) production, as well as substracts (wood) from species commonly found at the region (eucalyptus, bracatinga), and with great biological efficiency. The field essays were made in the "Experimental Farm Gralha Azul" of the Pontifical Catholic University of Parana (PUCPR), and the "seed" production, at the phytopatology laboratory. For the experimental evaluation the woods were arranged as a experimental poles, organized in a factorial 3x2x4, being 3 isolated, 2 substracts - eucalyptus and bracatinga and 4 replicates for each treatment. Bracatinga woods were not colonized by the isolates and it was not observed significant differences among the production of the tested isolates.

Keywords: Mimosa scabrela; Eucaliptus grandis; Shiitake.

\footnotetext{
${ }^{1}$ Eng.. Agrônomo, M.Sc Professor Adjunto de Fitopatologia da PUCPR.
}

2 Eng. ${ }^{2}$ Agrônomo e ex-bolsista de iniciação científica do CNPq. 


\section{Introdução}

A produção e consumo de cogumelos comestíveis no Brasil aumentou a partir da década de 70 , devido às suas propriedades nutricionais e medicinais (PAULA et al., 2001). Ishikawa et al. (2001) enfatiza o efeito medicinal do shiitake.

Segundo Abe (1995), a tecnologia de cultivo comercial restringe-se basicamente a Agaricus bisporus (Champingnon de Paris) e, devido à falta de informações técnicas, produtores adaptam de forma empírica técnicas desenvolvidas na Europa, Ásia e América do Norte.

No caso específico do Lentinus edodes, conhecido como shiitake, as informações científicas são raras, ocorrendo indicações para utilização de árvores exóticas da nossa flora, como substrato para o crescimento deste cogumelo (BONONI, et al. 1995). Portanto, a avaliação de espécies vegetais arbóreas associadas à seleção de isolados adaptados às nossas condições representam potencial na maximização da produção.

A região de Curitiba apresenta potencial de produção e comercialização deste cogumelo. Segundo informações obtidas no CEASA-PR, todo produto comercializado por este órgão provém de São Paulo.

A falta de conhecimento sobre os substratos indicados para o cultivo do shiitake, bem como isolados adaptados às nossas condições, conduz a problemas de produtividade.

O processo de produção deste cogumelo é relativamente simples, necessita de um local sombreado, como um sub-bosque, e umidade relativa em torno de $80 \%$. A inoculação normalmente é feita em toras de eucalipto ou castanheira, com o "spawn" ou "semente" produzido em substrato de serragem (EIRA; MINHONI, 1996).

O objetivo deste trabalho foi avaliar a produtividade de isolados de shiitake em diferentes espécies vegetais.

\section{Metodologia}

O trabalho de produção da semente foi executado no Laboratório de Fitopatologia do Campus São José dos Pinhais - PUCPR e a instalação, na Fazenda Experimental Gralha Azul - PUCPR, Município de Fazenda Rio Grande - PR.
Neste trabalho foram utilizados três tipos de isolados de shiitake: Le 96/14 STEL; Le 96/178 e Le 1/96 PUC. Os dois primeiros foram cedidos pela UNESP Botucatu e o terceiro foi isolado, a partir de basidiocarpo comercial, no laboratório de fitopatologia da PUCPR. Os isolados foram preservados pelo método de óleo de lujol (EIRA; MINHONI 1996). Para recuperar os isolados, utilizouse 0 meio de serragem-dextrose-ágar (250g de serragem de eucalipto, $20 \mathrm{~g}$ de dextrose e $15 \mathrm{~g}$ de ágar), incubados em câmara de crescimento (tipo B.O.D) a $25^{\circ} \mathrm{C}$ por três dias.

Para a produção do "semente", usou-se $50 \mathrm{~kg}$ de serragem peneirada de eucalipto (peneira com malha $5 \mathrm{~mm}$ ); $25 \mathrm{~kg}$ de farelo de trigo; $60 \mathrm{~L} \mathrm{de}$ água; $500 \mathrm{~g}$ de dextrose e $500 \mathrm{~g}$ de calcário dolomítico (PRNT 75\%). Homogeneizou-se serragem com o farelo, ao qual foi adicionada a mistura da água, dextrose e calcário (EIRA; MINHONI, 1996). Aproximadamente $500 \mathrm{~g}$ deste substrato foi colocado em sacos de polipropileno com capacidade de 2L e autoclavados por $1 \mathrm{~h}$ e $30 \mathrm{~min}$ a $\left(121^{\circ}\right.$ - 1 atmosfera). Após 24h, procedeu-se outra autoclavagem nas mesmas condições. Uma vez esterilizado, o substrato foi inoculado com os isolados, totalizando 40 sacos para cada isolado, que permaneceram em temperatura ambiente para colonização do substrato.

Os tratamentos consistiram-se em fatorial com os três isolados: Le 96/14 STEL; Le 96/178 e Le 1/96 PUC; duas espécies utilizadas como substrato: bracatinga (Mimosa scabrela) e eucalipto (Eucaliptus grandis) e quatro repetições. Cada tratamento era formado por seis toras de $1,20 \mathrm{~m}$ de comprimento, sendo selecionados de árvores com 8-12cm de diâmetro, com ausência de nós e bom estado fitossanitário.

Os furos foram feitos com broca de $12 \mathrm{~mm}$ e a profundidade do furo, $30 \mathrm{~mm}$. A distância horizontal dos furos foi de $15 \mathrm{~cm}$ e a distância vertical de $5 \mathrm{~cm}$. O número de furos em cada tora variou entre 40 a 50 .

A "semente" foi colocada com auxílio de um funil e compactada, dentro dos furos, com o bastão de vidro. Após a inoculação, realizou-se a vedação dos furos com parafina aquecida a $120^{\circ} \mathrm{C}$ em fogareiro a gás. Foram utilizados um arame com um pedaço de esponja de aço na ponta em forma de bola, para aplicação da parafina, cobrindo no mínimo três vezes o diâmetro do furo. 
Seis meses após a inoculação, procedeuse a imersão em um tanque com $2 \mathrm{~m}$ por $2 \mathrm{~m}$ revestido com lona preta. A acomodação das toras no tanque ocorreu em três etapas, para evitar contaminação entre os isolados. Primeiramente foram colocadas as toras com o isolado El 96/14 STEL, depois o isolado Le 96/178, e finalmente o isolado Le1/96 PUC. Cada isolado permaneceu 24h imerso em água potável.

Após o processo de imersão, as toras foram levadas para uma estrutura de madeira onde ficaram inclinadas a aproximadamente 60․ Depois de sete dias, realizou-se a colheita. O critério para a colheita foi o íleo (ou "chapéu"), expandido, porém não totalmente aberto, padrão de comercialização, determinando-se a massa por tora. A segunda indução ocorreu 21 dias após a primeira.

Os resultados foram analisados para determinação da análise de variância F-teste e para comparação entre as médias utilizou-se o teste de Tukey a $5 \%$.

\section{Resultados e discussão}

A produção do inóculo exigiu dupla autoclavagem para evitar a contaminação do subs- trato utilizado para o inóculo. Segundo Eira; Minhoni (1996), a autoclavagem por $2 \mathrm{~h}$ seria suficiente, porém, com o método adotado, obteve-se ausência de contaminação. Após 60 dias que as toras foram inoculadas, observou-se uma boa colonização nas toras de eucalipto, e nas toras de bracatinga o crescimento foi incipiente. Isto pode ter ocorrido devido a não adaptação dos isolados testados neste tipo de substrato, conforme verificado por Leatram; Grifin (1984); também ocorreu maior contaminação por fungos, conforme avaliação visual.

A Figura 1 demonstra a produtividade dos isolados de shiitake. Os isolados testados não colonizaram as toras de bracatinga, por conseqüência, não apresentaram produtividade. Rossi et al. (2001) relata a grande quantidade de substratos celulíticos possíveis de serem utilizados, porém esta espécie vegetal não foi colonizada.

A produtividade da primeira colheita foi menor do que na segunda, independente do isolado. Isto se deve à colonização incompleta do alburno, conforme relatou Royse et al. (2002). A partir da segunda, ocorre uma tendência de aumento da produtividade até o início do esgotamento do substrato.

\section{FIGURA 1 - Produtividade de Shiitake (Lentinula edodes) em diferentes substrados, após duas induções.}

Figure 1 - Shiitake (Lentinula edodes) productivity in different substrate, after two induction

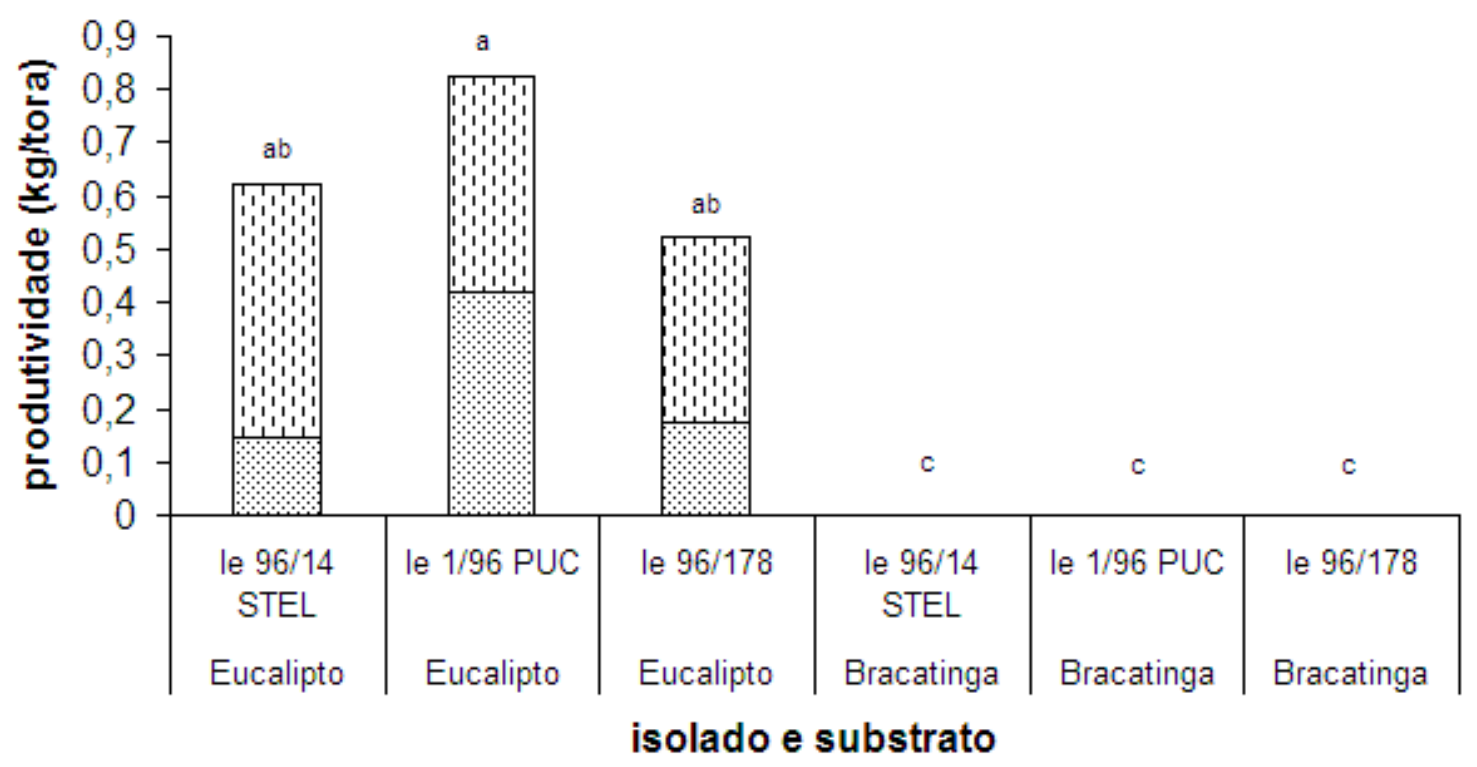


Não se observou diferença estatística significativa para os isolados testados nas toras de eucalipto.

\section{Conclusões}

Houve necessidade de dupla autoclavagem para completa esterilização do substrato usado na produção de semente de shiitake.

As toras de bracatinga não foram colonizadas isoladas de shiitake testados.

Os isolados testados não apresentaram diferença de produtividade.

\section{Referências}

$\mathrm{ABE}, \mathrm{E}$. Meio de cultura para isolamento de Pleurotus spp. Botucatu: Instituto de Biociências, 1996.

BONONI, V. L Cultivo de cogumelos comestíveis. São Paulo,SP: Ícone, 1995. p. 96-100.

EIRA, A. F; MINHONI, M. T. A. Manual do cultivo do shiitake. Botucatu: Fundação de Estudo e Pesquisas Agrícolas e Florestais, 1997. p. 138.
ISHIKAWA, N. K.; KASUYA, M. C. M.; VANETTI, M. C. D. Antibacterial activity of Lentinula edodes grown in liquid medium. Brazilian Journal of Microbiology, v. 32, p. 206-210, 2001.

LEATHAM, G. F. Adapting liquid spawn Lentinula edodes to oark wood. Applied Microbiology,

PAULA, D. P.; TARSITANO, M. A. A.; GRACIOLL, L. A. Viabilidade econômica do cultivo de shiitake em diferentes escalas de produção. Scientia Agrícola, v. 58, n. 2, p. 431-436, 2001.

ROSSI, I. H., MONTEIRO, A. C., MACHADO, J. O. Desenvolvimento micelial de Lentinula edodescomo efeito da profundidade e suplementação do substrato. Pesquisa Agropecuária Brasileira, v. 36, n. 6, p. 887-891, 2001.

ROYSE, D. J., RHODES, T. W., SANCHES, J. E. Vacuum-soaking of wood chip shitake (Lentinula edodes) logs to reduce soak time and log weigh variability and to stimulate mushroom yield. Applied Microbilogy and Biotechnology, v. 58, p. 58-62, 2002. 